\title{
Power Shifts, Multiple Audiences, and Credible Reassurance
}

\author{
Brandon K. Yoder
}

Australian National University. 


\begin{abstract}
It has been widely noted that rising states face great difficulty in credibly communicating benign intentions, due to strong incentives for hostile risers to misrepresent themselves while they are still gaining power. However, virtually all literature on power shifts and reassurance relates to bilateral interactions between a rising and declining state. This article presents a formal model showing that when more than one audience is involved, rising states have an additional means of communicating their intentions through simple, costless statements. In particular, if the preferences of the receivers are sufficiently divergent, the rising sender cannot simultaneously send cooperative public signals to both parties to avoid a balancing response. This reduces the riser's incentive to misrepresent its preferences, and lends credibility to its public statements of its intentions. The credibility of these signals is enhanced to the extent that they align with the preferences of the less-powerful receiver. The theory is illustrated by a case study of the Open Door Notes as a signal of US intentions at the turn of the 20th century, and applied to contemporary China's reassurance of Russia in the presence of the United States.
\end{abstract}


The extensive literature on interstate signaling has shown that reassurance is particularly difficult in the context of shifting power. Hostile or revisionist rising states face strong incentives to misrepresent themselves as having benign intentions, in order to avoid containment in the present and continue gaining power for the future (Levy 1987; Powell 1996, 1999; Copeland 2000, Wolford et al. 2011, Debs and Monteiro 2014). This misrepresentation makes it particularly difficult for others to infer a rising state's future intentions from its present behavior, since both compatible and incompatible risers are likely to behave cooperatively. As a result, a large segment of the theoretical IR literature has concluded that in the context of dynamic power, the international system is chracterized by prevalent and intractable security dilemmas, wherein states with compatible underlying goals end up in conflict due to a combination of future vulnerability and uncertainty about each other's intentions.

This paper presents a formal model which shows that in the presence of multiple receivers with divergent preferences, a rising state's cheap-talk reassurance signals are both informative and effective in forestalling preventive opposition. This striking result follows because whenever either of the receivers is sufficiently distrustful to take preventive action against the rising state, no signals exist that allow the rising state to avoid opposition from both receivers simultaneously. The sender must therefore choose which receiver it prefers to incur opposition from, and send a corresponding signal that will bring about that outcome. In this situation, rising states prefer to avoid opposition from the receiver who more closely shares their preferences, and to instead invite mutually-costly conflict with the receiver with whom their preferences are more at odds. This engenders incentives for the sender to honestly signal its type, and lends significant credibility to even costless, cheap talk reassurance signals under shifting power.

The model also yields several important auxiliary findings. First, although the rising state's cheap talk reassurance signals are sufficiently informative to forestall preventive opposition from one receiver, they are not fully credible. Instead, the rising state tempers its 
reassurances to the receiver whose preferences more closely match its own, in order to avoid alienating the other receiver. This leaves open the possibility that the sender is a moderate type whose preferences fall between the two receivers', and allows it to incur only partial opposition from the receiver with whom it is less compatible.

In addition, the model reveals that holding pessimistic prior beliefs confers a crucial advantage for eliciting credible signals of a rising state's intentions. This is because initial distrust allows the receiver to commit to preventive opposition if the sender does not issue credible reassurances, such that the sender cannot hope to avoid opposition by simply sending an uninformative moderate signal. Moreover, the information from the sender's signals is more beneficial when the receiver's priors are pessimistic than when they are optimistic. Because the initially-pessimistic receiver can commit to preventive opposition, it receives reassurance signals that are sufficiently credible to avoid conflict with compatible or moderate senders and to confidently identify and fully oppose highly incompatible senders. In contrast, an initially optimistic receiver elicits signals that only allow it to partially oppose highly incompatible senders, and still result in some degree of costly conflict with moderate senders that the receiver would prefer to accommodate.

These findings are an important contribution to the literatures on both power transitions and the security dilemma. Contrary to the widespread claim that states intentions are impossible to discern with significant confidence (e.g., Layne 1993; Mearsheimer 2001; Rosato 2015), the model below shows that in the presence of a third-party rival, a declining state can readily identify rising states who hold similar preferences through simple cheap talk signals, thereby avoiding conflict. Thus, the security dilemma operates only weakly in a multilateral setting, and great power conflict should occur only between states with truly incompatible goals. This is true even under shifting power, which has long been held to exacerbate the twin problems of uncertainty and vulnerability that drive the security dilemma.

To illustrate the broad applicability of the model's findings and their substantive importance, the paper concludes with two illustrative sketches of several empirical cases: The 
credibility of the costless "Open Door Notes" as a signal of US support for a liberal international economic order at the turn of the 20th century, and China's post-Cold War diplomatic reassurance of Russia in the presence of a unipolar United States.

\section{Literature}

This paper addresses interstate reassurance in the context of shifting power. Reassurance is a situation in which states are incompletely-informed about the compatibility of each other's goals - that is, whether they prefer the same outcome or different outcomes regarding an issue or set of issues. This type of uncertainty is particularly important for states in relative decline. As the distribution of power shifts, a declining state will become increasingly vulnerable to exploitation or revision by "hostile" rising states, i.e., those whose goals for the international order are relatively incompatible with the decliner's. ${ }^{1}$ This gives the decliner a strong incentive to oppose or contain hostile risers in the present, while it is still strong, in order to forestall their power gains and mitigate its own future vulnerability (Levy 1987; Copeland 2000). Yet the decliner obviously wants to avoid costly competition with "benign" risers that have similar inherent goals and will largely maintain its preferred order as they become more powerful (Glaser 2010). Thus, uncertainty about a rising state's goals presents the decliner with a strategic conundrum regarding whether and to what degree it should cooperate with the riser, versus attempting to suppress its power gains.

There is a large literature on interstate reassurance which shows how states with compatible goals can employ credible cooperative signals to readily identify each other (Osgood 1962; Jervis 1978; Kydd 1997b; 2000a; 2000b; 2005; Glaser 2010). Such signals include refraining from offensive military investments (Jervis 1978; Glaser 1994; 1997; Kydd 2005), forgoing low-cost opportunities for revision (Kydd 1997a), joining institutions that raise its

\footnotetext{
${ }^{1}$ The concepts "goals," "compatibility," and "cooperation" are defined above. "International order" is defined broadly, as the aggregation of all issues that states have preferences over (e.g., distribution of territory, terms of economic exchange, international norms, institutional rules, etc.). "Revision" refers to changes to the international order engendered by a rising state in accordance with its own goals that are harmful to the declining state's goals.
} 
opportunity costs of revision (e.g., Ikenberry 2001; Weinberger 2003), or bearing costs to support existing international rules and norms (e.g., Johnston 2003; Kydd 1997a). These signals are credible because they are "costly" - they carry high costs for hostile states that prefer an alternative international order, but are low-cost or even beneficial to benign types that inherently prefer the status quo (Fearon 1997).

Problematically, however, models of reassurance have generally assumed a static distribution of power. ${ }^{2}$ Yet power shifts engender barriers to a rising state's credible signals, making it difficult for declining states to determine which type of riser they are facing. Hostile rising states have strong incentives to misrepresent themselves as being benign as long as they are still relatively weak, by mimicking the cooperative behaviors of benign risers and refraining from attempting to revise the international order in accordance with their true goals (Layne 1993; Copeland 2000; Mearsheimer 2001; Edelstein 2002; Montgomery 2006; Rosato 2015). Although foregoing immediate revision is inherently costly to hostile rising states, for many these costs are outweighed by the prospects of avoiding opposition from the decliner and attempting revision under a more favorable distribution of power in the future.

Because cooperative signals are likely to be sent by both benign and hostile risers, declining states tend to be highly uncertain about the future intentions of cooperative rising states. As such, decliners face an onerous choice in response to cooperative signals: either preventively oppose the rising state and risk unnecessary, costly conflict with benign risers, or reciprocate cooperation and risk abetting the rise of a hostile state that will use its power to exploit the decliner in the future. Thus, a common claim is that sufficiently large power shifts can produce full-scale preventive wars between mutually-benign rising and declining states, due in part to the decliner's intractable uncertainty about the compatibility of a rising state's goals. ${ }^{3}$

\footnotetext{
${ }^{2}$ Kydd 1997a:148; 2005:202-204; Glaser 2010:110-112. Charles Glaser writes that a benign rising state can "pursue cooperative/conciliatory policies that [credibly] signal its type, thereby reducing the danger posed by its growing power" (Glaser 2010:110), while Andrew Kydd argues that cooperative signals make it possible for benign rising states "to demonstrate that their goals are so [compatible] that even with the anticipated accession of power, they will remain [cooperative]" in the future (Kydd 2005:204).

${ }^{3}$ See especially Copeland 2000.
} 
Recent work has made progress in identifying conditions and mechanisms that allow credible reassurance signals to be sent even in the inhospitable context of dynamic power (Debs and Monteiro 2014; Yoder 2019a; Yoder 2019b; Haynes 2020; Haynes and Yoder 2020). Yet each of these mechanisms require benign rising states to send costly signals of their type by exhibiting cooperative foreign policy behaviors that hostile risers would be unlikely to. Moreover, these signals are available to the rising state only when the declining state adopts particular foreign policy strategies that raise the costs of cooperation for hostile senders, and declining states only have incentives to adopt these strategies under particular circumstances. ${ }^{4}$ Even at that, the rising state's costly signals are often still insufficiently credible to completely forestall preventive conflict with an insecure declining state facing a large power shift. ${ }^{5}$

The model presented below, called the "multi-audience game," builds on this prior scholarship to show how even a rising state's costless, cheap talk reassurances can be credible in the presence of multiple receivers. ${ }^{6}$ When simultaneously facing two receivers whose preferences are at odds, it may not be possible for a rising sender to avoid opposition altogether. Any signal that adequately reassures one receiver would reveal the sender's preferences to be incompatible with the other receiver's, and incur opposition from the latter. When this situation obtains, the rising sender must choose which receiver it would rather come into conflict with. This generates a straightforward incentive for the sender to honestly signal which receiver its preferences align with more closely, and incur opposition from the less com-

\footnotetext{
${ }^{4}$ For example, one strategy for the decliner to elicit credible signals is to retrench from a particular region of high value to the rising state, to remove constraints over the riser's behavior and observe whether it continues to behave cooperatively given high freedom of action (Yoder 2019a). Yet retrenchment is only in the declining state's interests if several conditions are satisfied, such as the region of retrenchment having asymmetrically low value to the declining state and low impact on the distribution of power elsewhere.

${ }^{5}$ For example, another strategy by which a decliner can potentially elicit credible signals is to adopt an unconditional hedging strategy against the riser, exerting some limited degree of preventive containment even in response to cooperative signals (Yoder 2019b). This reduces the incentive for hostile risers to misrepresent their preferences by cooperating, since they stand to bear significant costs of incurring opposition regardless, and lends credibility to the riser's continued cooperation. Yet this hedging strategy also implies that even truly benign risers cannot fully avoid the costs of conflict, despite the information conveyed by their signals.

${ }^{6}$ In doing so, this paper adds to the burgeoning literature on credible cheap talk signaling mechanisms. See Sartori 2005; Kurizaki 2007; Ramsay 2011; Yarhi-Milo 2013; Bils and Spaniel 2017; Trager 2010, 2017; Joseph 2020.
} 
patible receiver. The indirect costs of incurring opposition from the other receiver therefore lend credibility to the sender's cheap talk reassurances.

The multi-audience game departs from existing multilateral signaling models, which assume a static distribution of power (Kydd 2000, 2005) and/or capture situations of coercive bargaining rather than reassurance (e.g., Wolford 2014; Trager 2015). ${ }^{7}$ In bargaining, a sender attempts to convince the receiver that their goals are highly divergent, and therefore that the sender is higly resolved to fight if its demands are not met. This contrasts with reassurance, wherein states attempt to signal that their goals are compatible in order to avoid confrontation in the first place. ${ }^{8}$ The model below therefore features a unique combination of reassurance signals, multiple audiences, and dynamic power.

Finally, the argument in this paper also diverges from the literature on audience costs, which shows how otherwise costless public statements by foreign policymakers can acquire credibility through the threat of punishment from the domestic selectorate (e.g., Fearon 1994; Weeks 2008) or the loss of a reputation for honesty in future diplomatic interactions (Sartori 2005). The mechanism in the model below is similar, in that the credibility of the sender's signals to its target audience derives from the presence of a third-party receiver. But instead of imposing conditional costs on the sender for sending dishonest signals of its type, the third party in the multi-audience game imposes immediate costs on the sender for signaling honestly. Thus, rather than the "tied-hands" credibility mechanism that charaterizes audience costs, the model below relies on "sunk cost" signals, in which the sender credibly conveys its type by demonstrating its willingness to incur costs from the third party. ${ }^{9}$ This bears some

\footnotetext{
${ }^{7}$ Wolford $(2014,2015)$ argues that the presence of a reluctant third-party ally can increase the credibility of a coercive threat, because signaling high resolve results in abandonment of the alliance by the third party. Trager $(2015,2017)$ argues that cheap talk extended deterrence threats can be credible because of the effect these statements have on an ally's behavior, encouraging the ally to risk precipitating a conflict that could entrap the sender. These indirect costs, in turn, lend credibility to the deterrent threat.

${ }^{8}$ On the distinction between bargaining and reassurance, see Kydd 1997:119; Yoder 2019a:928-929; Haynes and Yoder 2020. In bargaining, a sender attempts to convince the receiver that their goals are highly divergent, and therefore that the sender is higly resolved to fight if its demands are not met. This contrasts with reassurance, wherein states attempt to signal that their goals are compatible in order to avoid confrontation in the first place.

${ }^{9}$ On the distinction between tied hands and sunk costs, see Fearon 1997.
} 
similarity to Trager $(2010,2017)$, who shows how a cheap talk threat on one issue can credibly sink costs by incurring opposition from the receiver on other issues. However, Trager's models differ from the multi-audience game in several of the respects discussed above: they include multiple issues rather than multiple receivers, capture coercive bargaining rather than reassurance, and assume a static distribution of power.

\section{Model}

The multi-audience game has three players, a sender, $S$, and two receivers, $R_{A}$ and $R_{B}$. $R_{A}$ and $R_{B}$ have an asset in dispute, representing the broad shape of the international order across all issue areas, for which $R_{A}$ 's ideal point is 1 and $R_{B}$ 's is $0 .{ }^{10}$ These preferences are complete information to all actors. In contrast, $S$ 's ideal point, $g$, is private information, known only probabilistically to $R_{A}$ and $R_{B}$. The two receivers have common beliefs about the range of $g$ that is possible, $g \in[\underline{G}, \bar{G}]$. At the outset of the game, nature chooses $g$ from a uniform distribution, $\left[\underline{G}_{0}, \bar{G}_{0}\right]$, such that all values of $g$ between 0 and 1 are equally likely. Thus, each receiver's prior beliefs are $\underline{G}=\underline{G}_{0}$ and $\bar{G}=\bar{G}_{0}$.

[FIGURE 1 ABOUT HERE]

Figure 1 shows the extensive form game, which proceeds in two rounds. In the first round, $S$ sends one of three signals about its type, $\alpha, \beta$, or $\mu$. Signals $\alpha$ and $\beta$ indicate that $S$ 's preferences align with $R_{A}$ 's and $R_{B}$ 's, respectively, whereas signal $\mu$ indicates that $S^{\prime}$ 's preferences fall in an intermediate range. Crucially, none of these signals has any direct effect on any of the actors' payoffs, making them inherently costless, "cheap talk" signals.

\footnotetext{
${ }^{10}$ Conceiving of the asset at stake as the shape of the international order captures a wide range of situations in which outcomes can be either zero-sum or positive sum, in contrast to territorial issues which are virtually always zero-sum. Such situation often arise in great power politics, where major actors (such as contemporary China and the US or the Cold War US and Soviet Union) tend not to have designs on each others territory, but rather are concerned that their preferences are manifested in the institutional rules and norms that constitute the international order. See Bils and Spaniel 2017; Haynes and Yoder 2020; Priess and Schweller 1997.
} 
After observing $S$ 's signal, $R_{A}$ and $R_{B}$ simultaneously choose whether to oppose $S(O)$ or to accommodate it $(\sim O)$. Opposition by either receiver, $R_{i}$, inflicts cost $C$ on both $R_{i}$ and $S$, whereas accommodation imposes no costs on either. Opposition also alters the distribution of power, which is initially $p$ for $R_{A}$ and $1-p$ for $R_{B}$ in their bilateral interactions. If $R_{i}$ plays $O$, its power is reduced by $\pi$, and the other receiver's $\left(R_{j}\right.$ 's) power correspondingly increases by $\pi$. In addition, incurring opposition reduces $S$ 's power from $\bar{w}$ to $\underline{w}$, where $w \in\{\underline{w}, \bar{w}\}$ is the weight $S$ can bring to bear in the dispute between $R_{A}$ and $R_{B}$.

In the second round, $S$ chooses a degree of alignment with either $R_{A}$ or $R_{B}$. If $S$ fully aligns with $R_{i}$, then $w$ is added to $R_{i}$ 's second-round share of relative power, $p^{\prime}$, and subtracted from $R_{j}$ 's. However, $S$ can also "hedge" by adding only a portion of its power, $\phi \in[-1,1]$, to one receiver or the other, increasing $R_{i}$ 's share of second-round power by $\phi w$ and reducing $R_{j}$ 's by the same amount. Following $S$ 's alignment decision, the distribution of the asset is settled peacefully according to the weighted bilateral distribution of power between $R_{A}$ and $R_{B}$ (i.e., including $S$ 's alignment).

\section{Equilibria}

The model yields two classes of equilibria, depicted in Figure 2, one in which $S$ 's signals are informative and another in which they are uninformative. In both of these equilibrium classes, the second-round outcome is $p^{\prime}+w$ if $S$ fully aligns with $R_{A}$ and $p^{\prime}-w$ if $S$ fully aligns with $R_{B}$ (where $p^{\prime}$ is $R_{A}$ 's power relative to $R_{B}$ in the second round). Thus, $S$ fully aligns with one receiver or the other only when it cannot manipulate the balance of power to achieve its ideal point, and full alignment moves the outcome as close to $g$ as possible. On the other hand, $S$ hedges when its weight is sufficient to pull the settlement all the way to $g$, aligning with one of the receivers just enough to achieve its ideal outcome. In short, $S$ 's second-round move is to fully align with $R_{A}$ iff $g>p^{\prime}+w$, fully align with $R_{B}$ iff $g<p^{\prime}-w$, and to hedge by partially aligning with one receiver or the other when $p^{\prime}-w<g<p^{\prime}+w$. 


\section{[FIGURE 2 ABOUT HERE]}

Furthermore, because opposition is costly and the two receivers have common beliefs, it is never in equilibrium for both $R_{A}$ and $R_{B}$ to oppose $S$. This follows for the same reason that a range of mutually acceptable settlements always exists in the bargaining model under common beliefs in the absence of commitment problems. S's presence affects the receivers' payoffs only insofar as it shifts the terms of the negotiated settlement in round 2. Yet if the receivers agree on the expected effect that $S$ will have, then at least one necessarily expects $S$ 's presence to be beneficial. Given positive costs of opposition, it is a rational strategy for at most one receiver, and there is always a range of shared beliefs about $S$ under which neither receiver opposes.

$S$ 's first-round signals are uninformative when neither receiver would oppose $S$ given their common prior beliefs about $S$ 's preferences. This occurs when the upper bound on the receivers' prior beliefs about $g, \overline{G_{0}}$, falls between $\bar{G}_{A}^{*}$ and $\bar{G}_{B}^{*}$, the threholds below which $R_{A}$ opposes and above which $R_{B}$ opposes, respectively. ${ }^{11}$ Given that $R_{i}$ holds such priors, all types of $S$ can avoid opposition entirely by simply pooling on signal $\mu$ and sustaining $R_{A}$ and $R_{B}$ 's optimistic priors.

In contrast, $S$ 's first-round signals are informative when one of the receivers is relatively pessimistic, such that it would oppose $S$ given its prior beliefs (i.e., when $\bar{G}<\bar{G}_{A}^{*}$ and $R_{A}$ opposes or when $\bar{G}>\bar{G}_{B}^{*}$ and $R_{B}$ opposes). In this case, pooling on signal $\mu$ would incur opposition from the more pessimistic receiver. Yet this is out of equilibrium, because senders whose preferences align more closely with the pessimistic receiver would prefer to incur opposition from the other receiver. For example, suppose the receivers' prior beliefs dictate that $R_{A}$ would oppose. The range of senders who would then fully align with $R_{A}$ in the second round would prefer to be opposed by $R_{B}$ instead, because this would preserve $R_{A}$ 's power and allow $S$ to achieve an outcome closer to its ideal point. Senders in this range of $g$ would therefore prefer to signal honestly, revealing their true preferences and incurring

\footnotetext{
${ }^{11}$ These thresholds are defined in the appendix.
} 
opposition from $R_{B}$.

If senders that will align with $R_{A}$ separate and incur opposition from $R_{B}$, do all other types pool and incur opposition from $R_{A}$ ? This cannot be in equilibrium, because senders in the moderate range of $g$ would prefer to separate from those that are close to $R_{B}$, allowing the former to avoid opposition entirely. This separation would be robust, because senders close to $R_{B}$ would have no incentive to pool, as doing so would still incur opposition from $R_{A} \cdot{ }^{12}$

However, it also cannot be in equilibrium for all types of $S$ to signal honestly. Full separation, in which senders that would fully align with $R_{A}$ in round 2 send signal $\alpha$ and those that would fully align with $R_{B}$ send $\beta$, would allow senders in the middle range of $g$ to avoid opposition entirely by sending signal $\mu$. Yet this would generate incentives for senders in the range of $g$ close to $R_{A}$ 's ideal point to misrepresent and pool on signal $\mu$. As estabished above, this would sustain the receivers' priors and incur opposition from $R_{A}$, which is not in equilibrium.

The only remaining possibility is a mixed strategy equilibrium in which the range of sender closest to $R_{B}$ signals honestly and incurs opposition from $R_{A}$. All other types pool on $\mu$, such that the range of $S$ sending $\mu$ generates beliefs that make $R_{B}$ indifferent between $O$ and $\backsim O$. In response to $\mu, R_{B}$ mixes between $O$ and $\backsim O$ with a frequency that makes the range of $S$ that pools on $\mu$ prefer partial opposition from $R_{B}$ to full opposition from $R_{A}$.

This strategy profile gives no actor an incentive to deviate. $R_{A}$ fully opposes in response to signal $\beta$ and accommodates in response to $\mu$. $R_{B}$ accommodates in response to $\beta$ and partially opposes in response to $\mu$. Senders closest to $R_{B}$ prefer to incur full opposition from $R_{A}$ instead of partial opposition from $R_{B}$, because they benefit from the resulting increase in $R_{B}$ 's power relative to $R_{A}$. Conversely, moderate senders and those closest to $R_{A}$ are either indifferent to the bilateral distribution of power between $R_{A}$ and $R_{B}$ or want it to favor $R_{A}$, and therefore prefer partial opposition from $R_{B}$ to full opposition from $R_{A}$.

\footnotetext{
${ }^{12}$ Given that $R_{A}$ opposes when all types of $S$ pool on $\mu$, it also necessarily opposes the range of $S$ that pools on $\mu$ when those senders closest to $R_{A}$ 's ideal point separate by playing $\alpha$.
} 


\section{Discussion}

The top-line result of the multi-audience game is that when reassurance is beneficial to $S$, its cheap talk signals are both informative and effective in forestalling opposition. In the pooling equilibrium, all types of $S$ send signal $\mu$, which is therefore completely uninformative. But senders whose preferences closely align with $R_{A}$ or $R_{B}$ are only willing to pool because additional reassurance is unnecessary to avoid opposition from either receiver, given their prior beliefs. $S$ reveals no information because doing so would serve no purpose.

In contrast, when the receivers hold priors that would prompt one or the other to oppose, ${ }^{13}$ $S$ does stand to benefit from reassurance. In this case, credible signals are available. When $R_{A}$ holds pessimistic priors, signal $\beta$ informs the receivers that $S$ 's preferences are close to $R_{B}$ 's, and that $S$ intends to align with $R_{B}$ fully or to a large extent in round 2 . Signal $\mu$, conversely, informs the receivers that $S$ 's preferences are not close to $R_{B}$ 's, and that $S$ is either a moderate actor or one that is highly compatible with $R_{A}$. Furthermore, these reassurance signals are effective insofar as signal $\mu$ prompts $R_{A}$ to update its beliefs enough to shift its behavior from opposition to accommodation, while signal $\beta$ sustains accommodation from $R_{B}$.

Result 1: When the receivers' prior beliefs support opposition from either $R_{A}$ or $R_{B}$, S's reassurance signals are both informative and effective in eliciting accommodation from the initially-pessimistic receiver.

The mechanism driving the credibility of these signals is quite intuitive. With multiple receivers whose preferences are at odds with each other, a sender cannot avoid incurring at least some opposition from one receiver or the other. Given $R_{A}$ 's pessimistic priors, avoiding opposition requires $S$ to reassure $R_{A}$ that their preferences are at least minimally compatible: $S$ cannot simply pool in the middle and assuage $R_{A}$. But reassurance of $R_{A}$ would simultaneously alienate $R_{B}$, and prompt it to oppose. $S$ therefore faces a choice of

\footnotetext{
${ }^{13}$ Again, given that opposition is costly and the receivers hold common beliefs, there is no equilibrium in which both play $O$.
} 
which receiver it wants to incur opposition from, since it cannot completely avoid opposition from both. In this situation, $S$ prefers opposition from the receiver it will align against in round 2, because doing so will reduce that receiver's bargaining leverage and allow $S$ to achieve an outcome closer to its ideal point. This creates incentives for senders who will strongly align with either $R_{A}$ or $R_{B}$ to signal honestly, reassuring their future ally and imposing the costs of opposition on their future adversary. Such signals are informative precisely because they would not be sent by senders of the opposite type.

There are several other important and interesting results of the model. First, although $S$ 's reassurance of $R_{A}$ is both informative and effective, it is not completely credible. Senders that are most compatible with $R_{A}$ do not reassure $R_{A}$ by sending the strongest possible signal of their compatibility, $\alpha$. Rather, they pool with moderate senders by sending signal $\mu$. The rationale for this is that these senders want to adequately reassure $R_{A}$ without alienating $R_{B}$ more than necessary, which allows them to mitigate the degree of opposition they incur from $R_{B}$ as well. Thus, even if $S$ is highly compatible with $R_{A}$, it does not signal this. Instead, it signals only that it is not highly incompatible with $R_{A}$, while leaving open the possibility that it is also not highly incompatible with $R_{B}$. This carries the fascinating implication that in a multilateral setting, a rising state that truly share a certain receiver's goals will often still portray itself as a moderate to forestall opposition from third parties, even though more informative signals are available.

Result 2: When the receivers' priors support opposition from $R_{A}$, signal $\alpha$ is never sent. Instead, senders who intend to fully align with $R_{A}$ send only partially credible signals, pooling with moderate senders on signal $\mu$ and incurring partial opposition from $R_{B}$.

This raises the question of why senders that are highly compatible with $R_{B}$ do not exhibit similar equilibrium behavior. Why do they not attempt to mitigate opposition from $R_{A}$ by sending moderate signals, instead of signaling close alignment with $R_{B}$ ? The answer is that they cannot. Because $R_{A}$ holds pessimistic priors, it will oppose in response to moderate signal $\mu$ if that signal would also be sent by highly incompatible senders that are compatible 
with $R_{B} . R_{A}$ is only willing to accommodate in response to moderate signals if senders close to $R_{B}$ separate by playing $\beta$. Since senders close to $R_{B}$ will incur opposition from $R_{A}$ no matter what they do, they have no incentive to misrepresent, and simply signal honestly in equilibrium.

Result 3: When the receivers' priors support opposition from $R_{A}$, senders who intend to fully align with $R_{B}$ send fully credible signal $\beta$, and incur full opposition from $R_{A}$.

Intriguingly, this result reveals that pessimistic priors confer a crucial advantage on $R_{A}$, and that $R_{B}$ 's initial optimism carries a corresponding disadvantage. Because the receivers' shared beliefs are initially more pessimistic for $R_{A}$ than for $R_{B}, R_{A}$ can credibly commit to fully oppose if it is not adequately reassured. $R_{B}$, on the other hand, cannot. Thus, whereas senders close to $R_{B}$ cannot avoid opposition from $R_{A}$ no matter what they do, senders close to $R_{A}$ can partially misrepresent themselves as being moderate in order to lessen $R_{B}$ 's degree of opposition. $R_{A}$ 's commitment to opposition therefore allows it to completely avoid opposing moderate and highly compatible senders with whom it prefers to avoid conflict, while fully opposing highly incompatible senders aligned with $R_{B}$. Conversely, $R_{B}$ only partially opposes highly incompatible senders aligned with $R_{A}$, which it would rather fully oppose, while also incurring unwanted costs of conflict with moderate senders that it would rather not oppose at all.

Result 4: When the receivers' priors support opposition from $R_{A}$ and accomodation from $R_{B}$, S's signals allow $R_{A}$ to fully oppose senders who intend to fully align with $R_{B}$, and avoid opposing compatible or moderate senders who will hedge or align with $R_{A}$. Conversely, $R_{B}$ only partially opposes incompatible senders who intend to fully align with $R_{A}$, while also partially opposing moderate senders who will hedge. 


\section{Empirical Sketches}

\subsection{The Open Door Notes}

Throughout the second half of the 19th century, Britain maintained a liberal international economic order known as the "open door," characterized by low barriers to trade and nondiscriminatory access to markets. The London Spectator explained in 1898 that "the open door means is that traders of all nationalities shall have equal opportunities, not that there should be absolute freedom of trade," and Prime Minister Arthur Balfour specified that the "sole object" of the open door in China "was to insist that the policy of the Chinese government shall not be directed towards discouragement of foreign trade" (Allen 1955, 584-6).

However, by the late 19th century, Britain was declining relative to several states, including Germany, Russia, and the US. Britain was aware that its preferences for the open door were at odds with those of Russia's but was less confident about Germany and the US. The one arena where all four of these geographically far-flung states interacted on relatively equal terms was in East Asia. The commercial potential in the region was massive, and the ongoing decay of the late Qing empire had opened up new space for Western powers to compete for influence and to shape the rules of the regional order. US and German behavior in East Asia was therefore a crucial proving ground for their broader preferences for the global order, which, if Britain failed to contain them, would increasingly be manifested elsewhere as they gained power.

In fact, the British initially saw the US as far more likely than Germany to become a revisionist rival that would attempt to reshape Britain's preferred international order, and actually saw Germany as Britain's most likely ally in the increasingly multipolar international system. In the 1890s, Anglo-American relations remained "ever sensitive" and "requir[ed] careful cultivation, if only to prevent a further worsening" (Kennedy 1981, 95). British leaders saw the US as a growing economic rival for markets and investments and the Admiralty 
and War Office viewed US naval expansion in the early 1890s as "absolutely antagonistic." As late as 1895, British Prime Minister Salisbury considered "War with America... more than a possibility," and even viewed the US threat as "more of a reality than the Russo-French coalition" (Bourne 1967, 339-43). Conversely, British leaders viewed Germany as a likely supporter of the liberal economic order. Balfour wrote to Salisbury that "The great powers [i.e., Britain and Germany] primarily interested in the commerce of the world" felt drawn to join an alliance "for the purpose of seeing that China should not fall prey to any exclusive interest" (Grenville 1964, 169-170).

Why did Britain reverse its beliefs about the compatibility of German and American preferences with the open door in East Asia at the turn of the 20th century? The multiaudience game suggests that Britain could take the two states' public diplomatic statements at face value, given the presence of a great power rival with opposing interests. In East Asia, this role was served by Czarist Russia, which overtly pursued policies of imperial expansion and mercantilism, attempting to carve out a closed sphere of influence in China and Korea.

As such, the United States was able to credibly signal its preferences for the open door policy through costless statements. As early as 1898, the Senate Foreign Relations Committee publicly declared that if American commercial rights were threatened by Russian expansion, the US would "stand by [Britain] in her declaration that all the ports of China must be opened to all nations equally." But the major US signal came the following two years, in the form of the Open Door Notes of 1899 and 1900, which declared that all powers should adhere to non-interference in treaty ports and the universal application of Chinese duties (Adams 2005:165-186). The US corroborated these declarations by rhetorically opposing territorial concessions from China to Russia following the Boxer Rebellion and argued for reductions of the indemnity to be imposed on China for that incident. Importantly, however, the US did nothing to enforce the Open Door Notes, and as such they constituted a costless signal of American preferences. Yet this costless statement contrasted with those of Russia, Germany and Japan, which overtly sought territorial concessions and treaty ports. 
American support of the Open Door had a pronounced effect on British beliefs about the compatibility of US preferences in East Asia. Cecil Spring-Rice, a British diplomat, noted that "I know that both [Secretary of State John] Hay and [President Theodore] Roosevelt would like - not joint, but parallel action [with Britain in Asia] - and would be ready to cooperate in spirit if not in deed," and Colonial Secretary Joseph Chamberlain proposed that the Foreign Office "approach the United States officially" to "stand with us in our Chinese policy." In 1902 the Foreign Office reported to Parliament that "all through the difficulties in China we have worked on the most cordial terms with the United States. In almost every crisis... our representatives have been working together." Britain's Foreign Secretary, Lord Lansdowne, wrote privately that "we have every reason to believe that [the US] desires a maintenance of the status quo in the Far East" and that "we have noticed with satisfaction that the policy of the US government has from the first been favorable to the maintenance of Treaty rights and equal opportunity for commerce throughout China" (Perkins 1968, 211-218; Adams 2005, 172-177, 194-199).

The change in British beliefs had a pronounced effect on their response to rising US power in East Asia. Although US trade with China quintupled from 1897 to 1905 and American competition cut Britain's share of Japanese trade in half, friction between Britain and the US over commercial policy was almost entirely absent (Perkins 1968, 126). Even more tellingly, despite being formally allied with Japan after 1902, Britain consistently favored it relationship with the US, its recent rival, over its relationship with Japan. In 1905, Lansdowne insisted that the US be exempted from naval planning in the revised Anglo-Japanese alliance, and Grey confirmed in 1906 that Britain would abrogate the Anglo-Japanese Alliance if Japan were to go to war with the US (Perkins 1968, 230-2).

Moreover, British leaders were also convinced that they could trust the US to maintain the liberal international order more generally as it gained power, beyond East Asia. By 1903, Britain's only qualm about US behavior in might Latin America was that it might not be active enough in shaping the regional order. Prime Minister Balfour requested that 
the US "more actively interest themselves... in South America... to see that international law is observed" (Adams 2005, 70-71), and contrasted the US with "warlike and aggressive powers" like Germany and Russia. By 1904 Lansdowne advocated that "each government should take the other fully into its confidence... on all essential principles, there is unlikely to be any divergence between our policies or conduct." The Roosevelt Corollary was broadly cheered in Britain as a "definite statement of US intent" to make sure Latin American countries "pay their debts, keep their word, and act with decency," leaving "one less area of the world for Britain to police." Balfour reiterated that "We welcome any increase in the influence of the USA upon the great Western hemisphere... I believe it would be a great gain to civilization if the US were more actively to interest themselves in making arrangements," and his successor, Lord Grey, concurred that "these small [Latin American] republics...must succumb to some greater and better influence and it can only be that of the USA" (Adams 2005, 64, 76; Orde 1995, 33-4; Perkins 1968, 194, 127, 160-1).

\subsection{China's Post-Cold War Reassurance of Russia}

At the end of 1999, the relatively liberal Russian government under Boris Yeltsin was replaced by an illiberal one under Vladimir Putin. But like Yeltsin, Putin initially perceived the threat from the US as low upon assuming power. Thus, Putin's first few years constituted a "honeymoon period" in US-Russia relations, during which Russia weakened its opposition to NATO expansion, provided technical and diplomatic support for the US War on Terror (Wohlforth 2002, 202-6; Kuchins 2007, 323), and even expressed interest in joining NATO and developing a joint missile defense system with Europe (Wishnick 2001b, 801-802).

Putin initially perceived China's underlying goals quite negatively during this US-Russia "honeymoon period." Putin feared Chinese economic and demographic encroachment in the

Russian Far East, as well as Chinese domination of Northeast and especially Central Asia (Lo 2008, 11, 47-50, Ch. 4 \& 6). Although Russia was benefitting from its cooperation with China, China was gaining in relative terms, and Putin saw excessive risk in facilitating 
China's rise (Wishnick 2001b, 801-802). Thus, in his first few years after entering office, Putin pushed strongly for Russian integration with Europe while eschewing Chinese appeals for deeper cooperation (Wohlforth 2002, 202-206; Kuchins 2010, 40-41), and established the seven-member Collective Security Treaty Organization in 2002 as a hedge against growing Chinese influence in Central Asia and the SCO (Lo 2008, 99; Rozman 2010b, 143-144).

Importantly, China exhibited vigorous diplomatic efforts to reassure Russia during Putin's early years (Rozman 2010b, 143-144), but its statements were evidently not credible. Indeed, it was not obvious a priori that Chinese goals diverged from those of the US and were relatively compatible with Russia's (Lo 2008, 163-165). In bilateral economic relations, China was significantly less mercantilist than Russia, and often expressed dissatisfaction with Russia's degree of state intervention and lack of market forces (Rozman 2010a, 18). As of 2003 Russian leaders lacked "confidence in Chinese willingness to live up to its proclaimed support for the UN and multipolarity, if this risked the economic ties with the United States that were so crucial to [China's] development" (Ferdinand 2007, 849). Thus, "only from 2003 do we observe a notable quickening of the pace of improvement" in China-Russia relations (Rozman 2010a, 14).

The theory above suggests that China's reassurances were non-credible in the early 2000s in part because of the absence of a pronounced US threat to Russia. Russia's attempts to cooperate with the West in the early 2000s afforded China few opportunities to side with Russia in opposition to US preferences. According to Result 1, this would make it difficult for Russia to determine the extent to which Chinese preferences aligned with those of the US and diverged from its own, and thus how much China itself was likely to pressure Russia for economic liberalization as it gained power. Only with the reemergence of Russian perceptions of a high US threat after 2003 did policy space open up for China's public diplomacy to demonstrate that its goals diverged from those of the US, and were therefore closer to Russia's than was initially perceived. 


\section{High US threat and Russian optimism about Chinese intentions since 2004}

The US did not reciprocate Russian cooperation in the early 2000s. Under the George W. Bush administration, the US announced support for further NATO expansion in 2001, including into former Soviet states Latvia, Estonia and Lithuania (Menon 2009, 106), launched the Iraq war in 2003 in defiance of Russia and the UN, and withdrew from the Anti-Ballistic Missile Treaty and declared its intention to develop missile defense technology. These actions demonstrated that Putin's unconditional cooperation in the War on Terror had not earned him any favor with the US (Li 2007, 494-495; Menon 2009, 106). Worse, the Bush administration framed the Iraq War as part of a larger US grand strategy to promote democracy abroad, an implicit threat to the autocratic Putin. US support for the "color revolutions" in Ukraine, Georgia and Kyrgyzstan in 2004-2005 unambiguously revealed that American democracy promotion efforts were not limited to "rogue states" Iraq, Iran, and North Korea, but clearly extended to Russia and the countries in its sphere (Li 2007, 495; Deng 2007, 876; Kuchins 2010, 42). Consequently, by 2004 Putin understood the US to be implacably hostile to Russia in both geopolitical and ideological terms.

In conjunction with their heightened perceptions of US threat since 2004, Russian leaders have formed increasingly optimistic beliefs about China's intentions. "Senior Russian leaders and diplomats" now recognize that their Chinese counterparts share their preferences for "democratic principles of sovereignty, mutual respect of national interests, and...to deny legitimacy to...separate treatments of different categories of states" (Deng 2007, 881). According to Deng Yong (2007, 871), "Clearly, growing political trust explains the success" of China and Russia's resolution of longstanding border dispute in 2005. Moreover, this trust is "at bottom what drives Sino-Russian strategic partnership" (Deng 2007, 882), which "defines important issues the two sides see in similar and compatible...ways, and highlights points of convergence both sides expect to be long-lasting" (Menon 2009, 107). By 2014, Putin declared that China-Russia cooperation had "reached the highest level [in their] entire history" (quoted in Cox 2016, 327), and a recent assessment concurs that "historic Russian 
distrust of China has abated" (Charap et al. 2017, 25).

These beliefs are manifested more concretely in Russia's willingness to accept increasing degrees of vulnerability to China both militarily and economically. Economically, Russia has accepted increasingly asymmetric dependence on China. China is now Russia's largest trade partner, as well as an indispensable source of demand for Russia's two main exports: weapons and energy. Russia has dramatically increased its military dependence on China, conducting joint exercises and coordinating tactical and strategic planning to a degree characteristic of a de facto military alliance (Korolev 2020). In addition, Russian arms transfers have been almost single-handedly responsible for China's military modernization, radically abetting Russia's own military vulnerability to the rising superpower on its southern border (Menon 2009, 113-114). According to the CEO of Russia's national monopoly arms exporter, increased trust of China has been the key motivation: "If we work in China's interests, that means we also work in our interests" (quoted in Gabuev 2016, 24).

\section{The credibility of China's reassurance signals}

This shift in Russian beliefs about China's intentions is explained in large part by Result 1 above. The rapid reemergence of the US threat to Russia generated opportunities for China to credibly reassure Russia that their underlying goals were at least moderately compatible. China offered diplomatic support for Russian policies and preferences in opposition to those of the US. As Result 1 implies, these actions were credible signals because they would not be taken by a highly-incompatible China whose preferences accorded with those of the US. Instead, China showed itself willing to absorb substantial costs to reassure Russia by revealing that its preferences diverged from those of the US, and inviting American backlash against China. Russian leaders could therefore conclude that China was unlikely to side with the US in supporting interventions on political, economic, or humanitarian grounds against Russia's interests in the future.

Crucially, Chinese signals were limited almost entirely to diplomatic and institutional 
support for Russian preferences in opposition to the US. In 2003, new Chinese president Hu Jintao joined Russia in opposing the "illegal" US invasion of Iraq, which "amply demonstrated" to Russian leaders China's commitment to "restraining the United States through the UN mechanism" (Deng 2007, 883). Since 2007, China has also repeatedly joined with Russia in the UN to oppose Western-backed sanctions against authoritarian states for human rights and weapons proliferation violations (Kuchins 2007, 324; Cox 2016, 325). These costless diplomatic objections of US actions constituted a costly signal that China truly shared Russia's opposition to crucial components of the liberal international order in favor of strict norms of sovereignty and non-interference.

Even more concretely, China and Russia have formed their own non-binding or weakly binding institutions, most notably the SCO, to rhetorically promote shared goals that diverge from those of the US. In the midst of the Color Revolutions in 2005, the SCO supported Uzbekistan's authoritarian regime against Western sanctions, encouraged it to terminate US basing rights, and called for the withdrawal of US forces from Central Asia (Kuchins 2007, 324; Ferguson 2012). Importantly, China and Russia framed this demand around a "wider debate about the kind of international system they sought and the role the SCO might play in creating [it]" - one without American "monopoly and domination in world affairs" or interference in "the internal affairs of sovereign states," according to their joint 2005 statement. Thus, China's cooperation with Russia in the SCO signaled that it shared Russia's preference for security norms "very different to those found in the liberal and democratic West" (Cox 2016, 326; see also Deng 2007, 881-884).

Consequently, Russian leaders have formed genuine beliefs that China's intentions are benign. This is evidenced by Russia's investment in the expansion of the SCO, which facilitates Chinese political and economic influence in a region Russia considers a core national interest: ${ }^{14}$

"Russia has decided that the strategic complementarity of the two countries'...foreign

\footnotetext{
${ }^{14}$ This is also borne out in Russia's more recent support of China's "Belt-and-Road Initiative" for regional infrastructure investment that includes Central Asia (Charap et al. 2017).
} 
policies outweighs any concerns about Chinese involvement in post-Soviet Eurasia. China and Russia share threat perceptions about...Western attempts at fomenting popular revolt in order to install more popular governments. China (unlike the West, in Russia's view) would never attempt to overthrow sitting governments or pursue a democratisation agenda" (Charap et al. 2017, 34).

Indeed, according to a high-level Russian official, China-driven economic development projects "are in the interests of China, the Central Asian states, as well as Russia" (quoted in Kuchins 2010, 44).

China's statements against economic liberalization have also been credible signals that it will not support the US-led liberal international economic order, but rather that it will support rules conducive to the mercantilist "state capitalism" that Russia's authoritarian regime requires for its political survival. In 2004, despite "myriad difficulties in their [bilateral] trade relationship," China expressed vigorous diplomatic support for Russia's accession to the WTO with far fewer conditions than were required by the US and EU, "dispelling suspicion in Russia about China's sincerity" in supporting an economically illiberal Russia (Deng 2007, 885). China and Russia both openly denounced US efforts to broaden and deepen international economic liberalization through the Trans-Pacific Partnership, and have increasingly expressed alternative preferences for the international economic order in opposition to Western liberalism through the weakly institutionalized BRICs grouping of China, Russia, India and Brazil (Cox 2016, 326-7).

In sum, the presence of a US threat whose preferences are highly-incompatible with Russia's has given China the opportunity to demonstrate the "ceiling" on its own incompatibility with Russia: by offering diplomatic support for Russia in opposition to the US, China has demonstrated that its goals are significantly more compatible with Russia's. Russia's resulting optimism about China's intentions - not merely the incentive to balance a common US threat - has contributed to the increase in China-Russia cooperation since the end of the Cold War. 


\section{References}

[1] Bils, Peter, and William Spaniel. "Policy bargaining and militarized conflict." Journal of Theoretical Politics 29.4 (2017): 647-678.

[2] Bourne, Kenneth. 1967. Britain and the balance of power in North America, 1815-1908. University of California Press.

[3] Adams, Iestyn. 2005. Brothers Across the Ocean: British Foreign Policy and the Origins of Anglo-American "Special Relationship," 1900-1905. IB Tauris.

[4] Allen, H. C. 1955. Great Britain and the United States: A History of Anglo-American Relations, 1783-1952. New York: St. Martin's Press.

[5] Charap, Samuel, John Drennan, and Pierre Noël. "Russia and China: A New Model of Great-Power Relations." Survival 59, no. 1 (2017): 25-42.

[6] Copeland, Dale. 2000. The Origins of Major War. Ithaca, NY: Cornell University Press.

[7] Cox, Michael. "Not Just 'Convenient': China and Russia's New Strategic Partnership in the Age of Geopolitics." Asian Journal of Comparative Politics 1, no. 4 (2016): 317-334.

[8] Debs, Alexandre, and Nuno Monteiro. 2014. "Known Unknowns: Power Shifts, Uncertainty, and War." International Organization 68 (1):1-31.

[9] Deng Yong. "Remolding Great Power Politics: China's Strategic Partnerships with Russia, the European Union, and India." Journal of Strategic Studies 30, no. 4-5 (2007): 863-903.

[10] Edelstein, David. 2002. "Managing Uncertainty: Beliefs About Intentions and the Rise of Great Powers." Security Studies 12 (1):1-40.

[11] Fearon, James. 1994. "Domestic Political Audiences and the Escalation of International Disputes." American Political Science Review 88 (3):577-592. 
$[12]$ . 1995. "Rationalist Explanations for War." International Organization 49 (3):379-414.

[13] . 1997. "Signaling Foreign Policy Interests: Tying Hands versus Sinking Costs." Journal of Conflict Resolution 41 (1):68-90.

[14] Ferdinand, Peter. "Sunset, Sunrise: China and Russia Construct a New Relationship." International Affairs 83, no. 5 (2007): 841-867.

[15] Ferguson, Chaka. "The Strategic Use of Soft Balancing: The Normative Dimensions of the Chinese-Russian 'Strategic Partnership'." Journal of Strategic Studies 35, no. 2 (2012), 197-222.

[16] Gabuev, Alexander. "Friends with Benefits? Russian-Chinese Relations after the Ukraine Crisis." Carnegie Moscow Center, June 2016. http://carnegieendowment.org/files/CEIP_CP278_Gabuev_revised_FINAL.pdf

[17] Glaser, Charles L. 1994. "Realists as Optimists: Cooperation as Self-Help." International Security 19 (3):50-90.

$[18]$ . 1997. "The Security Dilemma Revisited." World Politics 50 (1):171-201.

$[19]$ . 2010. Rational Theory of International Politics: The Logic of Competition and Cooperation. Princeton, NJ: Princeton University Press.

[20] Grenville, J. A. S. 1964. Lord Salisbury and Foreign Policy: The Close of the Nineteenth Century. University of London.

[21] Haynes, Kyle . "A Question of Costliness: Time Horizons and Interstate Signaling." Journal of Conflict Resolution (Forthcoming), https://doi.org/10.1177/0022002718822719

[22] Haynes, Kyle and Brandon Yoder. "Offsetting Uncertainty: Reassurance under TwoSided Incomplete Information." American Journal of Political Science (Forthcoming). 
[23] Ikenberry, G. John. 2001. After Victory: Institutions, Strategic Restraint, and the Rebuilding of Order After Major Wars. Princeton, NJ: Princeton University Press.

[24] _______ 1978. "Cooperation Under the Security Dilemma." World Politics 30 (2):167-214.

[25] Johnston, Alastair Iain. 2003. "Is China a Status Quo Power?" International Security $27(4): 5-56$.

[26] Joseph, Michael F. 2020. "A Little Bit of Cheap-Talk is a Dangerous Thing: States Can Communicate Intentions Persuasively and Raise the Risk of War." Journal of Politics (Forthcoming).

[27] Kennedy, Paul M. 1981. The Realities Behind Diplomacy: Background Influences on British External Policy, 1865-1980. London: Allen \& Unwin.

[28] Korolev, Alexander. 2020. "How closely aligned are China and Russia? Measuring strategic cooperation in IR." International Politics (Forthcoming).

[29] Kuchins, Andrew. "Russia and China: The Ambivalent Embrace." Current History 106, no. 702 (2007): 321-327.

[30] __ _ _ _ "Russian Perspectives on China: Strategic Ambivalence." In The Future of China-Russia Relations, edited by James Bellacqua, Lexington: University Press of Kentucky, 2010: 33-55.

[31] Kurizaki, Shuhei. 2007. "Efficient Secrecy: Public versus Private Threats in Crisis Diplomacy." American Political Science Review 101(3):543-558.

[32] Kydd, Andrew. 1997a. "Sheep in Sheep's Clothing: Why Security Seekers Do Not Fight Each Other." Security Studies 7 (1):114-155.

[33] . 1997b. "Game Theory and the Spiral Model." World Politics 49 (3):371400. 
$[34]$ . 2000. "Trust, Reassurance, and Cooperation." International Organization $54(2): 325-357$.

$[35]$ . 2001. "Trust Building, Trust Breaking: The Dilemma of NATO Enlargement." International Organization 55 (4):801-828.

[36] _-___-_. 2005. Trust and Mistrust in International Relations. Princeton, NJ: Princeton University Press.

[37] Layne, Christopher. 1993. "The Unipolar Illusion: Why New Great Powers Will Rise." International Security 17 (4):5-51.

[38] Levy, Jack. 1987. "Declining Power and the Preventive Motivation for War." World Politics 40 (1):82-107.

[39] Li, Chenghong. "Limited Defensive Strategic Partnership: Sino-Russian Rapprochement and the Driving Forces." Journal of Contemporary China 16, no. 52 (2007): 477497.

[40] Lo, Bobo. Axis of Convenience: Moscow, Beijing, and the New Geopolitics. Washington, DC: Brookings Institution Press, 2008.

[41] Mearsheimer, John. 2001. The Tragedy of Great Power Politics. New York: Norton.

[42] Menon, Rajan. "The Limits of Chinese-Russian Partnership." Survival 51, no. 3 (2009): 99-130.

[43] Montgomery, Evan. 2006. "Breaking Out of the Security Dilemma: Realism, Reassurance, and the Problem of Uncertainty." International Security 31 (2):151-185.

[44] Orde, Anne. 1996. The Eclipse of Great Britain: The United States and British Imperial Decline, 1895-1956. Macmillan. 
[45] Osgood, Charles. 1962. An Alternative to War or Surrender. Urbana: University of Illinois Press.

[46] Perkins, Bradford. 1968. The Great Rapprochement: England and the United States, 1895-1914. Atheneum.

[47] Powell, Robert. 1996. "Uncertainty, Shifting Power, and Appeasement." American Political Science Review 90 (4):749-764.

[48] Politics. Princeton, NJ: Princeton University Press.

[49] Ramsay, Kristopher. 2011. "Cheap talk diplomacy, voluntary negotiations, and variable bargaining power." International Studies Quarterly 55 (4):1003-1023.

[50] Rosato, Sebastian. 2014/2015. "The Inscrutable Intentions of Great Powers." International Security 39 (3):48-88.

[51] Rozman Gilbert. "The Sino-Russian Strategic Relationship: How Close? Where To?" In The Future of China-Russia Relations, edited by James Bellacqua. Lexington: University Press of Kentucky, 2010a: 13-32.

[52] ________. Chinese Strategic Thought toward Asia. New York: Palgrave Macmillan, 2010b.

[53] Sartori, Anne. 2005. Deterrence by Diplomacy. Princeton, NJ: Princeton University Press.

[54] Schweller, Randall. 1994. "Bandwagoning for Profit: Bringing the Revisionist State Back In." International Security 19 (1):72-107.

[55] Stent, Angela E. The Limits of Partnership: U.S.-Russian Relations in the Twenty-First Century. Princeton University Press, 2014. 
[56] Trager, Robert F. 2010. "Diplomatic Calculus in Anarchy: How Communication Matters." American Political Science Review 104(2):347-368.

[57] Trager, Robert F. "Diplomatic Signaling among Multiple States." Journal of Politics 77 , no. 3 (2015): 635-647.

[58] Trager, Robert F. 2017. Diplomacy: Communication and the Origins of International Order. New York: Cambridge University Press.

[59] Weeks, Jessica L. 2008. "Autocratic audience costs: Regime type and signaling resolve." International Organization 62 (1):35-64.

[60] Weinberger, Seth. 2003. "Institutional Signaling and the Origins of the Cold War." Security Studies 12 (4):80-115.

[61] Wishnick, Elizabeth. "Russia and China: Brothers Again?" Asian Survey 41, no. 5 (2001b): 797-821.

[62] Wohlforth, William C. "Russia." In Strategic Asia 2002-03: Asian Aftershocks, edited by Richard Ellings, Aaron Friedberg, and Michael Wills, 183-222. Seattle: National Bureau of Asian Research, 2002.

[63] Wolford, Scott. "Showing Restraint, Signaling Resolve: Coalitions, Cooperation, and Crisis Bargaining." American Journal of Political Science 58, no. 1 (2014), 144-156.

[64] Wolford, Scott. 2015. The Politics of Military Coalitions. Cambridge University Press.

[65] Wolford, Scott, Dan Reiter, and Clifford Carrubba. 2011. "Information, Commitment, and War." Journal of Conflict Resolution 55 (4):556-579.

[66] Yarhi-Milo, Keren. 2013. "Tying Hands behind Closed Doors: The Logic and Practice of Secret Reassurance." Security Studies 22(3):405-435. 
[67] Yarhi-Milo, Keren. Knowing the Adversary: Leaders, Intelligence, and Assessment of Intentions in International Relations. Princeton University Press, 2014.

[68] Yoder, Brandon K. "Hedging for Better Bets: Power Shifts, Credible Signals and Preventive War." Journal of Conflict Resolution 63, no. 4 (2019a): 923-949.

[69] Yoder, Brandon K. "Retrenchment as a Screening Mechanism: Power Shifts, Strategic Withdrawal and Credible Signals." American Journal of Political Science 63, no. 1 (2019b): 130-145. 


\section{Figure 1: Extensive Form of the Multi-Audience Game*}

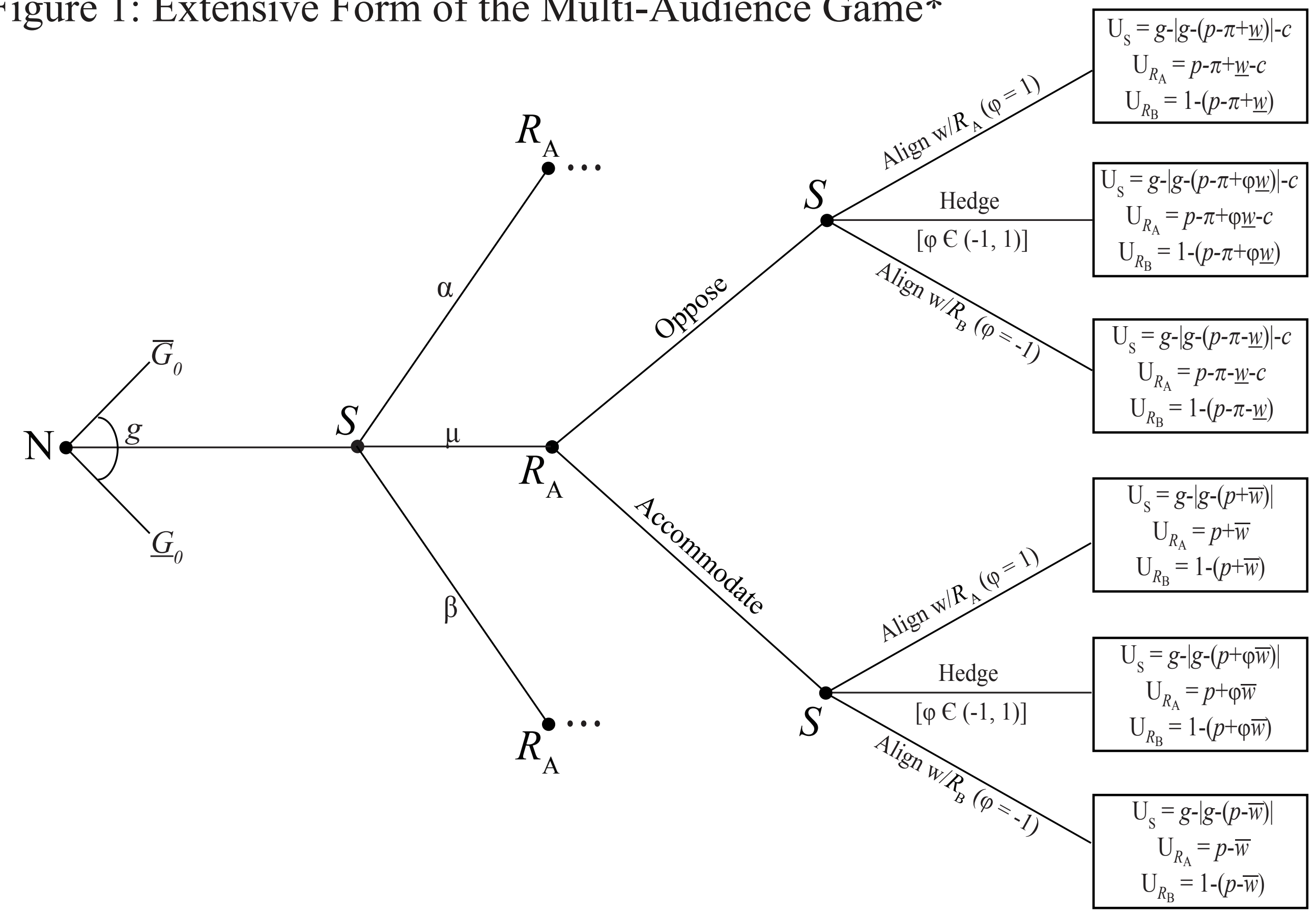

* To simplify the representation of the game, this graphic shows the game under the assumption that $R_{\mathrm{B}}$ accommodates. Since at most only one receiver ever opposes in equilibrium, this captures the de facto situation that $R_{\mathrm{A}}$ and $\mathrm{S}$ are facing (the situation is identical if $R_{\mathrm{A}}$ is assumed to accommodate, since the receivers' incentives are symmetrical). 


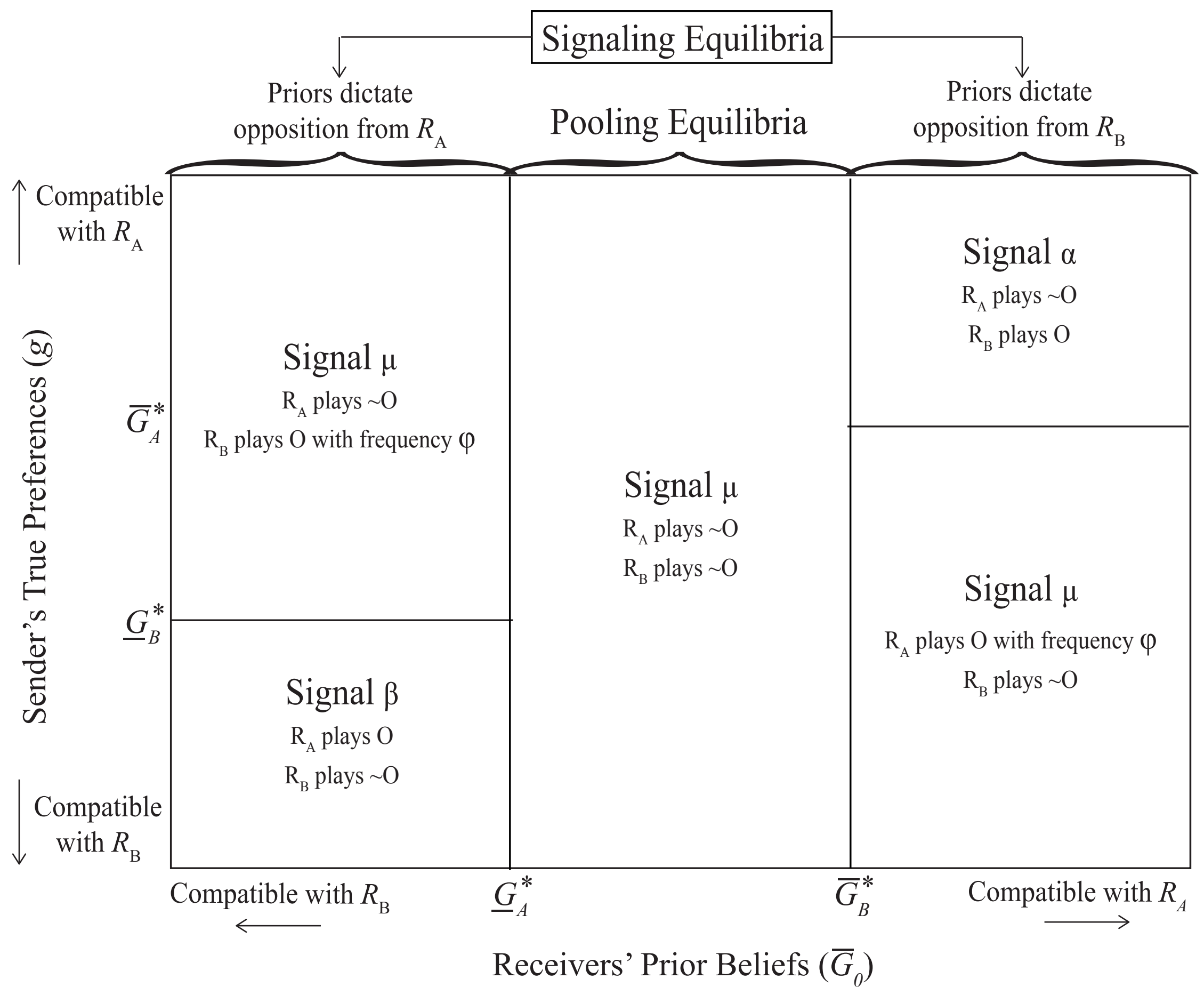

Figure 2: Equilibrium Map 